\title{
Substituindo a tentativa pela certeza no desenvolvimento da base do raciocínio lógico utilizando o jogo Sudoku nas escolas de $1^{\mathrm{a}}$ a $4^{\mathrm{a}}$ série do ensino fundamental
}

\author{
Marcelo Juste Lopes Alessandra Martins Coelho \\ Instituto Federal de Educação, Ciência e Tecnologia do \\ Sudeste de Minas Gerais - Departamento Acadêmico de Ciência da Computação, \\ 36180-000, Câmpus Rio Pomba \\ E-mail: marcelo_juste@hotmail.com \\ alessandra.coelho@ifsudestemg.edu.br
}

\section{RESUMO}

O Sudoku é um jogo criado nos Estados Unidos no final da década de 70. Consiste em uma matriz $9 \times 9$, subdividida em 9 regiões menores de tamanho $3 \times 3$, com algumas células preenchidas previamente. O objetivo é completar a matriz com números de 1 a 9 não podendo ter repetições em linhas, colunas e nas 9 sub-regiões da matriz. É um jogo de raciocínio lógico, sem necessidade de conhecimento matemático e, devido a essas características, vem sendo utilizado em escolas visando estimular o raciocínio lógico [7].

Em alunos do ensino fundamental, a matemática não está completamente relacionada com a forma de se obter respostas utilizando a lógica e sim um modelo imposto pelo professor. Isso limita sua forma de pensar, prejudicando-o a alcançar resultados de sucesso [4].

Em [8] menciona-se ser clara na teoria de Vygostsky a relação de brincar com a atividade infantil. O jogo é considerado por [6] como uma atividade necessária para o desenvolvimento da aprendizagem, tomando como base Piaget ao dizer que "os jogos são essenciais na vida da criança sendo a atividade lúdica o berço das suas atividades intelectuais, indispensável por isso, à prática educativa."

O raciocínio lógico necessário para jogar sokoban e sudoku foi analisado em [9]. Uma variação do sudoku, denominada killer sudoku foi apresentada aos alunos, que a utilizaram via web. Essa pesquisa concluiu que os alunos adquirem uma postura mais reflexiva quando estão diante de situações-problema. Outros trabalhos relacionados ao uso do jogo sudoku para auxiliar no ensino da matemática são [1], [2], [3] e [5].

Esta pesquisa propõe o uso do jogo sodoku por alunos das primeiras 4 séries do ensino fundamental de maneira que os alunos, em vez de chutarem os elementos, que eles selecionem os algarismos somente quando houver certeza, visando estimular o aluno a pensar de forma racional durante o jogo, pois fará com que ele utilize a lógica envolvida.

A tentativa durante a resolução não é válida para o desenvolvimento do aluno, portanto, não deve ser utilizada como método, sendo assim, é possível diversificar a forma de ensino mostrando aos professores novas opções de trabalho.

Como exemplo (Figura 1(a)), o aluno poderia tentar a resolução do sudoku substituindo o algarismo 1 nas casas permitidas (destacados em vermelho), ou seja, ele não pode ter certeza de sua única posição. Analisando o jogo como um todo (Figura 1(b)) o aluno poderia afirmar a posição do algarismo 7 , chegando à conclusão de que só há uma possibilidade para o algarismo 1. Isso mostra que este tipo de tentativa anterior não precisa ser utilizada para resolução do jogo. 
Figura 1- Exemplo do preenchimento de uma célula do jogo sudoku

\begin{tabular}{|c|c|c|c|c|c|c|c|c|}
\hline 8 & & & 4 & & 6 & & & 7 \\
\hline & & & & & & 4 & & \\
\hline & 1 & & & & & 6 & 5 & \\
\hline 5 & & 9 & & 3 & & 7 & 8 & \\
\hline 1 & & & & 7 & & & & \\
\hline 1 & 4 & 8 & & 2 & & & & 3 \\
\hline & 5 & 2 & & & & & 9 & \\
\hline & & 1 & & & & & & \\
\hline 3 & & & 9 & & 2 & & & 5 \\
\hline
\end{tabular}

(a)

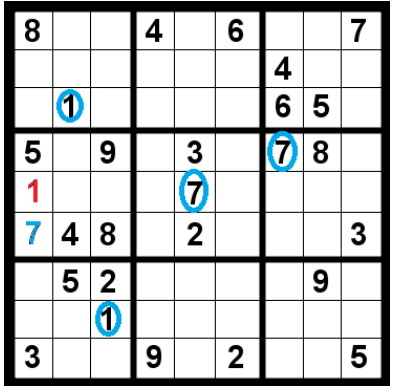

(b)

Legenda: (a) análise da resolução por tentativa.

(b) solução proposta pela metodologia

Palavras-Chave: Sudoku, Raciocínio lógico, Ensino Fundamental.

Agradecimento: Os autores agradecem à FAPEMIG e ao IF SUDESTE MG pelo apoio.

\section{Referências}

[1] A. Felix; G. Grebot, O Sudoku como ferramenta para o desenvolvimento de regras de lógica na aula de matemática. VII Congreso Iberomericano de Educación Matemática. Montevideo, 2013.

[2] C. E. R. Alves. Conceitos matemáticos e de computação aplicados ao sudoku. Integração, ano XIII, $\mathrm{n}^{\circ}$ 50, p.235-240, 2007.

[3] D. M. Alvarenga, et al. O Ensino de Matemática Através do Uso do Jogo Sudoku. In: XXXI Congresso Nacional de Matemática Aplicada e Computacional - CNMAC 2008, 2008, Belém - PA. CNMAC 2008, 2008.

[4] A. C. F. Ebner, "Jogo Sudoku em crianças com 6- 7 anos: modos de realizar, compreender e intervir”, Dissertação de Mestrado, Instituto de Psicologia - USP, 2013.

[5] G. H. J. Silva, M. B. F. Leite. Explorando conteúdos matemáticos dos ensinos fundamental e médio a partir de modelos matemáticos. Anais do XI V Encontro de Iniciação Científica da PUC Campinas, 2000.

[6] P. C. Moura, A. J. Viamonte, Jogos matemáticos como recurso didático. Revista da Associação de Professores de Matemática, Lisboa, 2006. 9 p.

[7] R. Wilson, "Como solucionar sodoku: guia passo a passo". São Paulo: Marco Zero, 2006.

[8] T. M. Kishimoto et al., Jogo e letramento: crianças de 6 anos no ensino fundamental. Educação e Pesquisa, São Paulo, v.37, n.1, 220p. 191-210, 2011.

[9] V. L. B. Pereira; F. M. Schaf. Os jogos sudoku e sokoban como mediadores no processo de ensino-aprendizagem de matemática. III Escola de Inverno de Educação Matemática. $1^{\circ}$ encontro Nacional PIBID - Matemática. Santa Maria - RS. 2012. 